\title{
Transforming Technical Services
}

\section{Evolving Functions in Large Research University Libraries}

\author{
Jeehyun Yun Davis
}

Technical services functions in academic libraries have evolved in response to fiscal pressures and advances in technology. In this study the author investigates how technical services in large research university libraries are adapting to support the changing roles of academic libraries. The author conducted hour-long phone interviews in early 2014 with the representatives from nineteen out of the twenty-five university libraries in the Technical Services Directors Large Research Libraries Interest Group. This paper presents the results and discussion based on the interview data: use of the name, Technical Services; new and emerging functions of technical services; organizational structure of technical services units; change drivers that are affecting technical services now, and those that will soon; and challenges in managing technical services. Five models of a technical services organizational structure were developed from participants' organizational charts and interview data. This research also highlights the skills needed among technical services personnel.

Jeehyun Yun Davis (j.davis@austin.utex as.edu) is Head, Cataloging and Metadata Services, University of Texas Libraries, Austin, Texas

Manuscript submitted May 20, 2015; returned to author for revision July 23 , 2015; revised manuscript submitted August 21, 2015; accepted for publication September 23, 2015.
A cademic libraries continually confront challenges that are primarily driven A by technological innovation and budget constraints. Library administrators try to find ways to meet these challenges by transforming and streamlining workflows and prioritizing objectives through their strategic planning processes and other mechanisms. Academic libraries' strategic priorities subsequently impact every other area within the libraries, and technical services is no exception. The labor intensive processes prevalent in technical services have been negatively impacted by ongoing reductions in staffing and decreasing budgets. This phenomenon has resulted in various challenges and opportunities in technical services. There are great opportunities for current technical services operations to improve inefficient and antiquated workflows, to renew and develop proper technology skills among staff, and to transform the structure of technical services to effectively deploy staff to manage the transformation of its functions through reorganization.

The major shift from print to electronic resources (e-resources), including born-digital resources, in library collections over the last decade has impacted every area in academic libraries. While anecdotal evidence is shared with regard to the ways in which certain specific functions or areas in technical services are changing, it is much more of a challenge to grasp the big picture of the various changes transpiring in technical services. 
The motivation for this study started from a simple question: "How is technical services changing?" Although the question itself seems naïvely simple, it led to some fundamental questions about the changing nature of technical services and helped formulate the research questions of this study:

1. What is the name of the functional area that is traditionally known as technical services?

2. What are the current and emerging functions of technical services?

3. What are the organizational structures of technical services? How often do libraries reorganize their technical services and why?

4. What are the factors that drive technical services to change?

This study revealed the complex nature of current technical services, including its functions and the dynamics of technical services in the context of other units both within and outside libraries. The author analyzed the organizational structure of nineteen large research university libraries based on the Technical Services Directors of Large Research Libraries Interest Group ${ }^{1}$ and conducted one-hour phone interviews with representatives of these libraries to explore how technical services is changing. The research findings will provide empirical data to library administrators and technical services managers as they undertake the transformation of their technical services operations. They will also benefit by examining different models of technical services organizational structure and different names that identify technical services as they explore various ways to reposition technical services in their libraries. The findings on diversified current and emerging technical services functions will help them reexamine their own technical services functions and explore different strategies to integrate technical services functions to support libraries' new and emerging services. Additionally, technical services librarians and staff will benefit by gaining a better understanding of the types of skills that are needed to support the changing roles of technical services. This paper is divided into four sections: literature review, description of the research method, presentation of results and discussion, and a conclusion.

\section{Literature Review}

The functions and organizational structure of technical services have been frequently discussed in the literature. It is broadly agreed that technical services usually includes acquisitions and cataloging functions. In Technical Services in Libraries, published in 1954, Tauber observed, "Although the technical services division varies in different libraries, the general basic pattern is to combine the acquisition department with the cataloging department." ${ }^{\text {2 }}$ Some authors still support this basic pattern of technical services in the more recent literature. Evans, Intner, and Weihs in 2002 defined acquisitions and cataloging as the two traditional areas within technical services. In their view, the acquisitions section is responsible for procurement of library materials and cataloging for organizing and preparing library materials. ${ }^{3}$

However, it is worth noting that the composition of technical services has always varied, particularly among university libraries, regardless of period. Tauber admitted,

It has been pointed out that so far as university libraries are concerned, there is no standard pattern in the grouping of the various departments into functional units. Such factors as tradition, personnel, physical quarters, financial support, types and distribution of collections, and the personalities, qualifications, and attitudes of administrative officers and staff have accounted for variations in organization. Most large libraries today, however, approximate a functional organization, with separate departments for acquisitions, cataloging, binding, photography, reference, circulation, and other units. ${ }^{4}$

Gorman made a similar observation: "Although there is broad agreement that the term technical services embraces acquisitions (defined narrowly) and bibliographic control (cataloging and classification), the definition of the rest of technical services varies from one period to another and from one library to another." With this observation, Gorman offered quite a broad definition of technical services. He defined technical services as "all the tasks carried on in a library that are concerned with the processing of library materials to make them accessible to the users of the library."6 Gorman's definition of technical services encompasses not only those functions related to acquisitions and cataloging but also those related to circulation and stack maintenance, preservation, and collection development.

Adding more complexity to the discussion of what constitutes technical services, there has been much talk about where technical services functions should reside in the library. Intner and Johnson made the following observation:

When interpreted broadly, the technical services department is likely to be large and busy, handling many different types of tasks. To the extent that functions eligible to be administered under technical services are placed under reference/public services or are separate departments, technical services will be smaller and more focused. No one method of organization is best, nor will a good 
method remain good for all the time. It behooves administrators to be open-minded about adopting different organizational styles to improve their bibliographical outputs and the working environment. ${ }^{7}$

There are various factors that influence where technical services resides and how it is structured; for example, organizational culture, campus environment, campus and library leaders' vision for the library, etc. A recent article by Laskowski and Maddox Abbott observed these factors through examining the evolution of technical services at the University of Illinois at Urbana-Champaign Library over the last few decades. ${ }^{8}$ The article focused on the Library's reorganization activities between technical services and public services that began in 1978 in an attempt to decentralize cataloging functions and to embed cataloging activities in subject areas of public services. It offered a comprehensive historical context in the course of changes that were made in both technical and public services in the Library over the years, and underscored the importance of acknowledging and cultivating expertise in both services.

Efforts to redesign and reorganize technical services divisions have actively occurred in recent years and are well documented in the literature. ${ }^{9}$ Reviewing the organizational structure and reorganizing technical services have become common practices in libraries in recent years. Workflow efficiency, staffing shortages, and staff skills have become the dominant topics among technical services professionals in response to fiscal and technological challenges. Much effort has been made to tackle these issues and different approaches have been explored to manage technical services effectively through reorganization activities. One notable phenomenon is implementing a team-based work environment in technical services to increase communication and interaction among staff. Some technical services units in academic libraries have created a team environment that has flattened the traditionally hierarchical technical services structure. ${ }^{10}$ In her article in 2011, Zhu concluded that "in the past 10 years, more and more technical services in academic libraries started to use teams and more than half of the survey respondents regarded the impacts of the use of teams on their technical services as at least moderately positive. It is very likely that more technical services in academic libraries will use teams in the future." ${ }^{\prime 1}$

Demand-Driven Acquisition (DDA) may have a significant impact on the functions of acquisitions and collection development. The DDA model, also known as Patron-Driven Acquisition, has become a popular topic at library conferences and in the professional literature. Due to the issues and challenges regarding library storage space for physical books, academic libraries started investigating the circulation and usage rate of their physical collections, weeding them to send unused or infrequently used items to remote storage facilities. After conducting a circulation analysis in her library, Cramer argued that "money and labor spent on the non-circulating books were completely wasted. For the books that circulated once, the cost-per-use is the full price of the book, plus processing costs, shelf space costs, etc." ${ }^{\prime 2}$ According to Cramer, DDA can solve these problems and stop libraries from purchasing library resources that may never be used. Dzwig claimed that the traditional collection development model is too costly for modern libraries. New collection development models involving DDA can resolve the issues derived from the traditional model and better incorporate users' needs in the decision making process. She argued, "A modern library must be better adjusted to the users' needs. It's time for a shift toward demand driven library services." ${ }^{.13}$ It is obvious that many librarians approve of the DDA model and see it as "a fundamental mental shift" in how we select and purchase library collections ${ }^{14}$ However, some have expressed their concerns with this approach. Walters cautioned us: "PDA's emphasis on efficient information delivery may come at the expense of broader institutional goals." ${ }^{15}$ Regardless of the pros and cons of the DDA model in the areas of acquisitions and collection development, the model has great potential to change the traditional ways of how libraries select and acquire library resources.

Some notable developments at the national and international levels have greatly affected academic libraries and sped up changes in technical services. In 2009, the International Federation of Library Associations and Institutions (IFLA) issued the Statement of International Cataloguing Principles, a new set of international cataloging principles "that are applicable to online library catalogues and beyond." 16 The purpose of this statement is to replace and broaden "the scope of the Paris Principles from just textual works to all types of materials and from just the choice and form of entry to all aspects of bibliographic and authority data used in library catalogues." ${ }^{, 17}$ The Cataloguing Principles serve to "increase the international sharing of bibliographic and authority data and guide cataloguing rule makers in their efforts to develop an international cataloguing code."18 This effort to provide universal and timely cataloging principles coincides with the development of Resource Description and Access (RDA), an international cataloging content standard, to "provide a comprehensive set of guidelines and instructions on resource description and access covering all types of content and media." ${ }^{\prime 19}$ With these efforts to develop international cataloging principles and a content standard for bibliographic data, the Library of Congress (LC), the Program for Cooperative Cataloging (PCC), and other cataloging communities in the US, started their preparation for testing and implementing RDA as their new content standard for descriptive metadata around 2009, thereby replacing the Anglo-American Cataloging Rules that largely focus on describing textual works. These 
developments were derived from the social, economic, and technological changes in how knowledge and information are disseminated and are a result of the efforts to provide new ways to manage bibliographic data in the twenty-first century.

Developments such as replacing outdated cataloging principles and codes consequently raised concerns about the absence of a technological infrastructure capable of supporting the full extent of these changes. The long-standing library practice for encoding and exchanging bibliographic records using the Machine Readable Cataloging (MARC) standard is problematic in the current web environment, where MARC data are invisible to the major search engines such as Google, Yahoo, and Bing. This is a problem for academic libraries because these search engines often are the starting point of their users' research. ${ }^{20}$ In 2002, Tennant wrote, "The problems with MARC are serious and extensive, which is why a number of us are increasingly convinced that MARC has outlived its usefulness." ${ }^{\text {21 }}$ He proposed building "a bibliographic metadata infrastructure that likes any metadata it sees, and can easily output simple records when needed, or complex records when called upon to do so." ${ }^{22}$

The discussion around replacing MARC became more concrete when LC initiated the Bibliographic Framework Initiative (BIBFRAME) and hired Zepheira in 2012 to develop a bibliographic data model that would be based on linked data. The model and the feedback from the information community are expected to "eventually ensure a flexible bibliographic framework, a robust reference code, a supporting infrastructure for deployment, and an effective migration plan to support the community in making a transition from MARC to a new framework." ${ }^{23}$ The emergence of linked data as the baseline of a new bibliographic framework has been strongly emphasized in recent years. Schreur sees the use of linked data for academic research data and bibliographic data as a revolution. He believes that "Moving to a linked data environment ... has the power to completely alter the way academia creates, maintains, and explores data." ${ }^{24}$ Implementing new bibliographic standards and building new technical infrastructures to take advantage of the current web technology undoubtedly impacts many functional areas of academic libraries, including technical services.

While academic libraries explore new models and technical infrastructures it is worthwhile to note the growing need to support and curate research data generated by faculty and researchers. In 2010 Carlson and Garritano anticipated,

The changes in how research is done under the e-science paradigm will have an effect on how the library carries out its mission of supporting the research and information needs of the university. The nature of scholarly communication, for example, is already undergoing dramatic change in response to technological advances, and the spread of e-science research models will only accelerate the pace of these changes. ${ }^{25}$

As the nature of scholarly communication changes, academic libraries have a unique opportunity to play a major role in curating and managing research data by advancing and refining their existing expertise in the areas of information description and organization, preservation, discovery, outreach, and instruction, many of which are traditionally part of technical services. However, this opportunity is not easily achievable and presents challenges. Carlson and Garritano argued that "the traditional organizational structures and culture of academic libraries pose barriers to the library becoming more actively involved in building cyberinfrastructure and supporting e-science," and they underscored the need for rethinking and adjusting the organization and staffing models of academic libraries. ${ }^{26}$

Active discussions on involving technical services in the curation and management of research data have appeared in more recent literature. In 2012, the Association of College and Research Libraries (ACRL) released a research report, "Academic Libraries and Research Data Services: Current Practices and Plans for the Future."27 This report provided a thorough analysis of the current services offered by academic libraries and the services that they plan to offer in the future to support research data management. The report identified that technical services is currently involved in providing the following research data services (RDS) or plan to offer in the future:

- Providing technical support for RDS systems (e.g., a repository, access and discovery systems)

- Deaccessioning/deselection of data/data sets for removal from a repository

- Preparing data/data sets for deposit into a repository

- Creating or transforming metadata for data or data sets

- Identifying data/data sets that could be candidates for repositories on or off campus ${ }^{28}$

Additionally, two consulting services, "Consulting with faculty, staff, or students on data management plans" and "Consulting with faculty, staff, or students on data and metadata standards" that are categorized under Informational/ Consulting Services can be easily seen as part of technical services' purview. Hunter's study found similar results to the ACRL report and identified the following services currently provided by technical services to support academic libraries' digital publishing initiatives: metadata/cataloging, scanning/ digitization, loading content into online platforms, technical maintenance of online platforms, technical maintenance 
of server/hardware, working/liaising with partners outside the library, promotion/marketing, and formatting/editing. ${ }^{29}$ Considering its expertise in information organization, preservation, discovery, and information retrieval, this kind of services related to digital resources management will continue to be developed in technical services.

It is evident that academic libraries are in the midst of a paradigm shift and are constantly assessing and reassessing their services and organizational structures to support the changing nature of scholarly communication. Constituting a major part of academic libraries, technical services inevitably stands in the middle of these changes, and efforts to transform technical services are frequently observed among academic libraries. In Ruschoff's interview with Mandel and Kurth about the creation of the Knowledge Access and Resource Management Services (KARMS), a new division that replaced NYU Libraries Technical Services, Mandel said, "We knew we needed to move forward with our Technical Services in a different way ... We decided to reframe the expectations of Technical Services and to do it in an expansive way that allowed for growth and change. We wanted to look anew at the entire 21st century act of acquiring, managing, and providing access to content available through the Libraries. ${ }^{\text {"30 }}$ The interview indicates that creating a new framework to transform traditional technical services requires a lot of effort, including:

- meticulous and thoughtful planning based on critical analysis of existing as well as future services

- clear communication and staff buy-in through staff discussion

- encouraging creative thinking, cultivating a culture of collaboration, and creating a flexible working environment

- developing strong leadership including middle management

- creating and hiring positions with both technological and operational skillsets ${ }^{31}$

This interview provides unique perspectives describing the approaches and thought processes at the top level behind the creation of KARMS at the NYU Libraries. The creation of KARMS is an audacious attempt to transform a traditional technical services units and to build a flexible division that offers crucial expertise in knowledge access and resource management in an academic library.

\section{Research Method}

This research was conducted between January 2013 and June $2014 .{ }^{32}$ The goal was to study the overall functions and organizational structures of current technical services and to identify possible future directions for technical services in academic libraries. The author chose twenty-five university libraries from the Technical Services Directors of Large Research Libraries Interest Group as a "purposive sample."33 The author chose a semiconstructed interview method for data collection. Unlike structured interviews such as a questionnaire, a semiconstructed interview provides flexibility "in terms of the order in which the topics are considered, and, perhaps more significantly, to let the interviewee develop ideas and speak more widely on the issues raised by the researcher.",34

The research was conducted in three phases. In the first phase, the author contacted the twenty-five individuals in the sample and solicited their participation in the study via email. Participants were asked to submit their technical services organization charts and to commit to an hour-long interview. Nineteen individuals (76 percent) sent the author their organization charts and agreed to participate in a phone interview. The organization charts were reviewed before the interviews and helped the author compose interview questions.

The phone interviews-phase two of the projectoccurred in January and February 2014. The participants received a set of interview questions (see appendix) before the interviews to prepare and have time to think about their responses. Based on preliminary analysis of the organization charts and depending on how the participants answered the interview questions, the author slightly adjusted the order and syntax of the interview questions as needed. Each interview was recorded for the next phase.

The third and final phase of the research consisted of analyzing the interview data. The author used a direct coding method for data coding. Instead of transcribing each recorded interview, data was coded directly from the audio files. Following the steps of the interview data management process proposed by Halcomb and Davidson helped save time transcribing the interviews and ensured the accurate recording of verbal interview data through an iterative process of data management. ${ }^{35}$ The author used Microsoft Excel to code and manage the interview data. The coding themes were organized in the same way that the interview questions were asked (see appendix). To achieve the highest possible levels of accuracy and objectivity, the author contracted a graduate student assistant to code the recorded interviews first. Then the author personally listened to the recordings to validate and amend the interview data input by the graduate assistant. Additionally, the author constructed five organizational structure models of technical services during this phase. These models were synthesized from the interview data and the organizational charts of the nineteen participating libraries. Detailed information about the models can be found below in the Results and Discussion section. 
Table 1. Names Representing Technical Services

Name

No. of Occurrence (\%) $(N=19)$

Acquisitions \& e-Resource Management / Data Management \& Access ${ }^{*}$

Bibliographic Services

$2(10.5 \%)$

Collection Development / Materials Processing ${ }^{*}$

Collection Management and Scholarly Communication

$1(5.2 \%)$

Information Processing Center

$1(5.2 \%)$

Information Resources

$1(5.2 \%)$

Knowledge Access and Resource Management Services

Technical Services $+*$

* At these two institutions, the acquisitions department and cataloging department are not in the same division.

* Some libraries include "Library," or "Central," in front of the name Technical Services; one library has a subtitle, "Acquisitions Resource Management" after the name Technical Services; in some libraries the name, "Technical Services" appears as part of a compound name; for example, "Information and Technical Service," "Technical Services and System," "Collections, Technical Services, and Scholarly Communication," and "Collection and Technical Services."

\section{Results and Discussion}

\section{Use of the Name "Technical Services"}

Some have questioned whether the name "Technical Services" is adequate to represent the work in a "new user environment." 36 There is a perception that the name does not convey the activities or functions that take place in technical service units, and as a result some libraries have renamed their technical services divisions in an attempt to represent their operations and responsibilities more clearly to others. Intner suggested "names that include words such as 'collections,' 'data,' 'database,' 'bibliographic control,' 'management,' 'computer,' etc." 37 as alternatives, and some libraries have renamed their technical services areas using some of these suggestions. However, many libraries still have an area named Technical Services in their organization charts.

The interview data indicate that 52.6 percent of the participating libraries either have a department or division called Technical Services, or include Technical Services as part of a compound name (see table 1). The main reason that these libraries continue to use the name "Technical Services" is because they have not found an alternative name that better describes their work. Most of the interviewees expressed that they are open to changing the name, but noted that it is difficult to find a representative name that describes the various functions of technical services as a whole. One participant responded, "For right now, we are sticking with Technical Services as our name because everyone knows what it means and we don't have to explain it." Another participant said, "We have not made any attempt at all to change the name. ... Every time somebody says tech services I know exactly what that is and I think that's useful.
There may be eventually another name that we wanna go by that we are nationally recognized, I think that will be fine. I am not opposed to changing the name. I think it just makes it a little confusing sometimes that we all call ourselves something different."

While some libraries continue to use the name "Technical Services," others have changed it as part of a broader reorganization effort or with a specific intent. One participant explained the reason: "The intent [of changing the name] was to be as inclusive as we could be, so that we could partner with as many other groups within the library as we could to help them think through discovery and access to the full range of the resources they are interested in."

As noted in the Literature Review section, what constitutes technical services also varies by library. One notable phenomenon that is in contrast to the Literature Review is the reporting structure of acquisitions and cataloging departments. It is commonly agreed that the basic composition of technical services includes both acquisitions and cataloging functions, but the interview data revealed that two of the participating libraries separate cataloging and acquisitions into different divisions and there is no collective area that represents the traditional concept of technical services composed of acquisitions and cataloging (see table 1).

\section{Current Functions}

The range of functions in technical services is extensive and varies by library. In some libraries, technical services functions are limited to acquisitions and cataloging, while in other libraries, technical services encompasses a wide variety of functions such as circulation, collection development, and remote storage management (see table 2). Technical 
services functions among the participating libraries are mostly centralized, with a few exceptional cases. The following areas generally fall into these cases:

- Special collections, archives, manuscripts: Acquisitions, cataloging and managing gifts/exchanges often occur in these areas, separated from the central technical services. In addition to creating MARC records, some of these areas are involved in creating nonMARC metadata such as Encoded Archival Description.

- Special libraries (e.g. law, music, medical): Because the materials that these libraries collect require specialized knowledge and skill, they tend to operate their own technical services work independent from the central technical services. Most law libraries generally do not belong to the main library system.

- Area studies (i.e. global studies): Non-Roman language areas such as East Asian, South Asian, Middle Eastern, and Slavic Studies are likely to operate their own technical services work because they require special language skill to perform acquisitions and cataloging functions.

- Government documents/Maps: Acquiring, cataloging, classifying, and preserving these materials require somewhat different processes from general library materials, and most libraries tend to have their own government document unit to process these materials.

- Vendors: Libraries use shelf-ready services from various vendors that supply batch cataloging records and physical processing. To a certain degree, vendors are involved in the selection of library materials through approval plans. Some libraries also use contract cataloging services for their cataloging backlog.

- Digital library/IT: In some libraries, non-MARC metadata management including non-MARC metadata creation happens in the digital library or Information Technology (IT) unit.

It was difficult to categorize common technical services functions from the interview data because there was significant variation in the range of technical services functions among the participating libraries. However, the author was able to make some observations about current technical services functions in libraries. First, libraries are attempting to centralize technical services functions across their organizations while still maintaining separate technical services operations in the exception areas discussed above. The consolidation of technical services functions is being driven by the desire to increase consistency and efficiency and to reduce costs. Separate technical services operations among special libraries and library units can be costly and can cause
Table 2. Current Functions of Technical Services

Access services (including Circulation/Course reserve/Electronic reserve/Resource sharing)

Acquisitions (including Ordering, Receiving, Claiming, Serials checkin, and Invoicing/Payment)

Authority control

Batch cataloging (including Batch loading and maintenance)

Collection development

Copyright

Data curation

Data management

Digitization

Discovery tools (e.g., Summons)

E-resources management (including access and maintenance)

Gifts/Exchange

Google Books Library Project

Identity management

ILL/Document delivery

ILS management

IR management and outreach

Library systems

Licensing of e-resources (including consortia licensing)

Mail room

MARC metadata (including Copy/Complex/Original cataloging, Classification/Subject analysis, and Cataloging maintenance)

Non-MARC metadata (including metadata consultation, maintenance, policy, and practice)

Physical processing (including marking and plating)

Preservation (including Binding/Repairing and Conservation work)

Post-cataloging processes

Remote storage

Scholarly communication

Shelf-ready service

Single e-book purchase

Stack maintenance

User experience

Web archiving

Note: The italicized functions indicate newly added functions of technical services in the last three to five years.

communication issues. Reduced staffing in technical services also motivates the effort to centralize technical services.

Second, it seems to have become a routine practice in technical services to assess existing workflows to make minor adjustments or to undertake a wholescale reorganization process. Libraries often re-allocate staff to cope with staffing losses within technical services. They frequently 


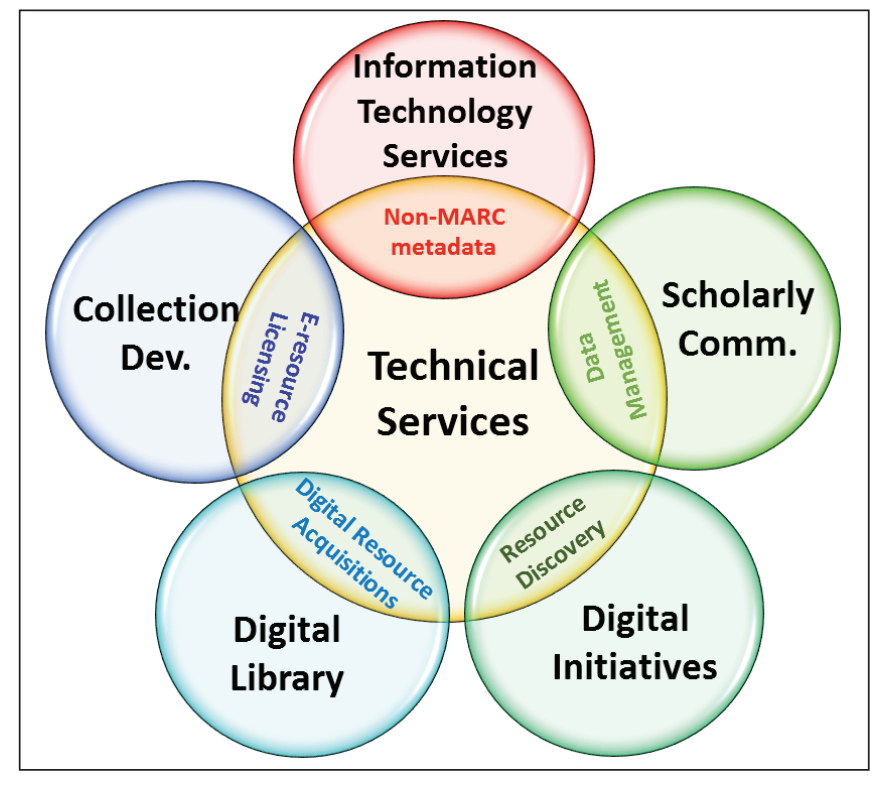

Figure 1. Technical Services Collaborative Functions with Different Library Units

review existing job descriptions and create a new position when there is an opportunity for a position opening in technical services.

Third, it is evident that most libraries have made a major shift from print to e-resources in their collections budget. However, reassigning staff to accommodate this change is occurring slowly, because library staff lack the relevant skills to manage e-resources, including licensing. Managing nonMARC metadata is another growing area where library staff often lack relevant skills, such as those pertaining to reusing existing bibliographic data through data transformation.

Fourth, new and emerging functions in technical services appear to be driven by e-resources. The italicized functions in Table 2 indicate newly added functions in technical services in the last 3-5 years. Most, if not all, are related to e-resources. These new and emerging functions of technical services - for example, managing a digital repository, building a web-archiving program, implementing linked data, and creating a digital curation program-demand technology skills that were not required in technical services in the past.

Lastly, libraries are increasingly emphasizing collaboration among units and departments within the organization. The conventional technical services functions related to acquiring, organizing, and preserving library materials no longer occur completely within technical services. Figure 1 describes some examples of technical services' functions that occur either outside of technical services or in collaboration with technical services. Library functions, such as managing non-MARC metadata, enhancing resource discovery, acquiring digital resources, providing data management, and managing e-resource licensing are complex and require specialized skills and knowledge. Depending on how a library is organizationally structured and what skills are available in technical services, these types of functions demand collaborative work across the library (see figure 1).

The trends observed above pose numerous challenges and have often resulted in technical services reorganization. Throughout the data analysis process, it was evident that fiscal constraints (due primarily to decreasing library budgets) and technology innovations are the two major factors that have prompted various changes in the functions of technical services. As a result, the organizational structure of technical services is becoming more complex and intertwined with the rest of the library as its functions evolve.

\section{Organizational Structure}

The organizational structures of the participating libraries are strikingly different, and it is almost impossible to discern a common organizational structure in technical services among them. As discussed in the previous sections, there is no consensus about what constitutes technical services and its functions. However, it is quite obvious that the areas of technical services are often being restructured to mirror the libraries' priorities and to reflect changing external factors such as the fiscal environment and technological innovations. While the core mission of academic libraries-to support research and teaching by collecting, organizing, and preserving information and making it accessible and discoverable-generally remains the same, the ways and means of fulfilling this mission have been drastically changing. Keeping up with the rapidly changing academic environment and addressing and implementing necessary changes in technical services is a big challenge for technical services administrators. The multifarious organizational structures among the libraries indeed demonstrate the microcosm of changing academic libraries in the recent years.

To better understand the organizational structures of the participating libraries, the author constructed five technical services models from the nineteen organization charts and the interview data. The intent of this modeling exercise is to explore different types of organizational structures of technical services in academic libraries. For the purpose of modeling, the author focused on the reporting pattern of the most commonly known technical services functions, "acquisitions" and "cataloging/metadata." Because the terms used in this modeling can cause confusion and have different meanings to different audiences, the following definitions were drawn:

- Division: An area that is managed by an Associate Director (AD) or Associate University Librarian (AUL).

- Department: An area that directly reports to an AD/ AUL. 


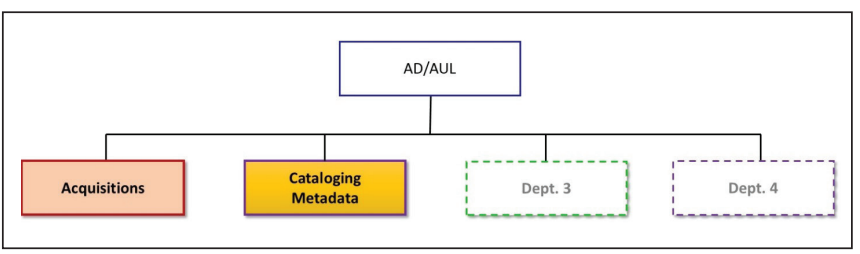

Figure 2. Model 1. AD/AUL for Multiple Departments Model: $A D / A U L$ of the area of technical services manages additional $\operatorname{area}(s)$

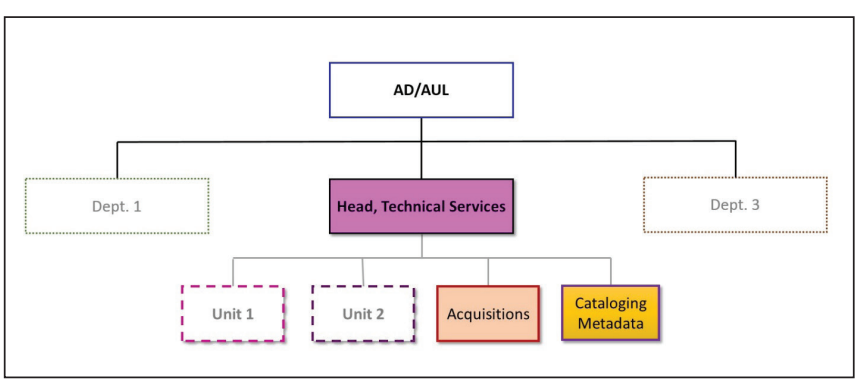

Figure 4. Model 3. Technical Services as a Department Model: Technical Services report to AD/AUL as a department along with other departments that report to the same AD/AUL

- Unit: An area that belongs to a department.

- Acquisitions: This term represents functions related to acquiring library resources, including ordering, invoicing, claiming, etc. It may or may not include the e-resources licensing function.

- Cataloging/metadata: This term represents functions related to knowledge access, bibliographic data description, control, and management.

In the AD/AUL for Multiple Departments Model (Model 1), the acquisitions and cataloging/metadata directly report to an $\mathrm{AD} / \mathrm{AUL}$, along with other department(s) (see figure 2). In this model, the AD/AUL is responsible for other library functions beyond technical services. This is the most common structure found in the participating libraries (11 out of $19,57.8$ percent). The range of the areas that the $\mathrm{AD} /$ AUL of technical services governs varied by library. Some AD/AULs have a wide range of responsibilities from collection management, preservation, document delivery, and access services to scholarly communication, library technology, special collections, and copyright, while others have one or two additional areas.

Model 2 describes the conventional technical services organizational structure in which an AD/AUL governs the functional areas of acquisitions and cataloging/metadata (see figure 3). This technical services structure is familiar to many library personnel and was previously the most common technical services organizational structure. Three libraries have this structure. Though the structure itself seems quite

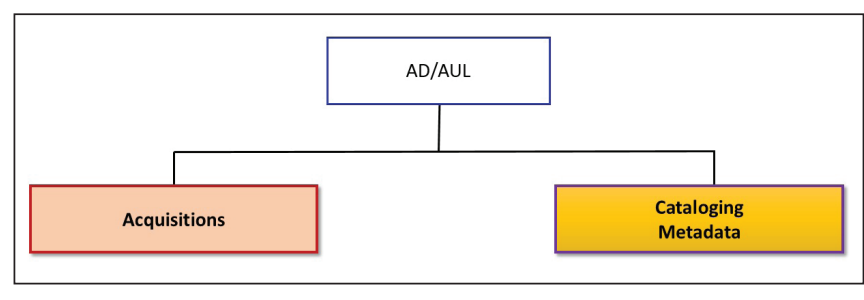

Figure 3. Model 2. Conventional Technical Services Model: AD/ AUL governs the areas of cataloging/metadata and acquisitions

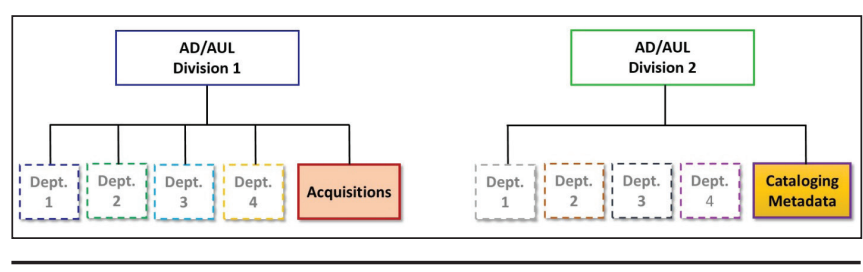

Figure 5. Model 4. Modularized Technical Services Model: Acquisitions and Cataloging/Metadata report to a different AD/AUL

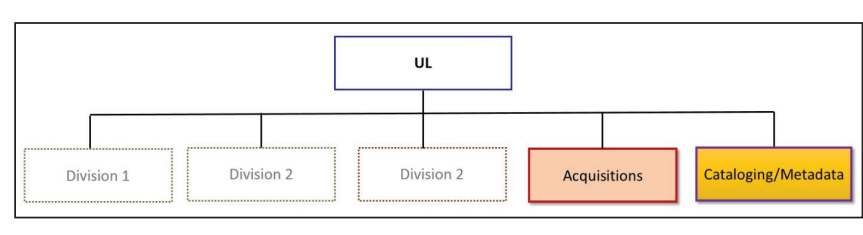

Figure 6. Model 5. Flat Reporting Model: The areas of acquisitions and cataloging/metadata report directly to University Librarian along other divisions

straightforward, in this model the functions within these two areas are much more complex and are evolving beyond traditional technical services functions, including software assessment, metadata consultation, e-resources management, etc.

There are two libraries that fall into the pattern of Model 3, Technical Services as a Department Model. In this structure, Technical Services as a whole is a department that reports to an AD/AUL along with other departments that report to the same AD/AUL. Unlike Model 1, in which the AD/AUL directly oversees technical services, there is one more layer of management that governs the functions of technical services, creating a more hierarchical reporting structure.

Model 4 is a somewhat unfamiliar structure and two libraries represent this pattern. It has long been a conventional practice that acquisitions and cataloging/metadata are closely located to each other and report to the same $\mathrm{AD} /$ AUL. One commonality between these two libraries is that cataloging/metadata reports to an AD/AUL who also governs the area of library technology, and acquisitions report to an AD/AUL who manages library content and collection. 
The last model is found in only one library. Acquisitions/ collection and cataloging/metadata report directly to the University Librarian.

Regardless of the rationale behind each individual library's organizational structure, the responsibilities of $\mathrm{AD} / \mathrm{AULs}$ in general have expanded in many libraries as discussed in Model 1. The most logical explanation of this phenomenon may relate to the two major external factors, budget constraints and technology, which were discussed in the previous section. A library can reduce the number of highly paid administrators by combining divisions under one AD/AUL. New and emerging library functions, largely driven by technology innovations, create different types of work in academic libraries and provide the rationale for the organizational structure of the AD/AUL for Multiple Departments Model among the libraries. Another phenomenon that is worth noting in terms of the organizational structure of technical services is frequently occurring reorganization efforts among the libraries. Twelve out of nineteen participating libraries reorganized their technical services operations within the last five years and one library was in the process of reorganizing its technical services at the time of the interview.

When asked about a plan for reorganization in the next three to five years, fourteen libraries said a reorganization was either definite or likely. During the interviews, various reasons for reorganizing technical services were identified:

- Directive from the top

- Changes in administrative leadership positions

- Rapidly growing e-resources in library collection and the need to make a shift in staffing to accommodate this change

- Use of vendor services for certain technical services functions to save money

- Need/Desire to increase efficiency and to create a more flexible organizational structure

- Staffing changes through retirements and/or resignations

- Merge among technical services areas across the library

- Implementation of a new ILS system

The rapidly changing technical services environment provides both challenges and opportunities for libraries. It is obvious that libraries are making great efforts to meet the challenges and find ways to transform their organizational structure. One participant described a positive experience with technical services reorganization that helped create a much more "grassroots and horizontal organization" where staff have a lot more freedom to express their opinions. He described, "the reorganization kind of broke us loose from the way we had done things . . . it fostered this culture of innovation. It fostered this attitude that it's OK to change and the change doesn't have to come from the top. So, if there were things that weren't working really well, in the new model people sat down and talked to their colleagues. . . . More than anything, the ability for the staff to say 'let's find a better way to do it' has been the major outgrowth of the reorganization."

\section{Skills}

While reorganizing technical services may provide opportunities to streamline workflows and improve communication among staff, there is great need for new skills to support the evolving technical services functions. Table 3 lists desirable skills in technical services staff from the interview data. Skills such as being "detail-oriented" and "foreign language skill" are common requirements that have appeared in typical job descriptions in technical services for many years. However, many skills in the list are not necessarily traditional skills that technical services required or preferred in the past.

The skills in table 3 can be broadly divided into two categories: hard skills (i.e., skills obtained through learning that are easily quantifiable or measurable) and soft skills (i.e., interpersonal or people skills, which are subjective skills that are harder to quantify). In table 3 , the italicized skills indicate soft skills, and the rest are hard skills. Many of the hard skills related to technology (e.g., database skill, linked data/ semantic web skill, programming skill, discovery system skill, etc.) were frequently mentioned as the most desirable skills in technical services during the interviews. The list of the desirable hard skills shows that there is a great demand for different types of technology skills in current technical services operations. In addition to technology skills, the interviewees identified skills related to non-MARC metadata management, foreign language resources, project management, e-resource licensing, and data management as the most critical hard skills in technical services. A striking aspect of this list is the number of desirable soft skills that libraries need in technical services. In the past, certain soft skills-for example, the ability to work independentlywere required in technical services, but today there are a larger number and a wider variety of soft skills that are desirable. Many technical services job responsibilities formerly involved working independently rather than in a team environment. This has changed as technical services functions have evolved, and collaboration with other units and departments is often required, as demonstrated throughout this article.

The desirable hard and soft skills in technical services are a clear indication of the changing nature of technical services' role in academic libraries. Work in technical services is becoming technology-centric, and library projects and initiatives that involve technical services have become more 
Table 3. Desirable Skills in Technical Services

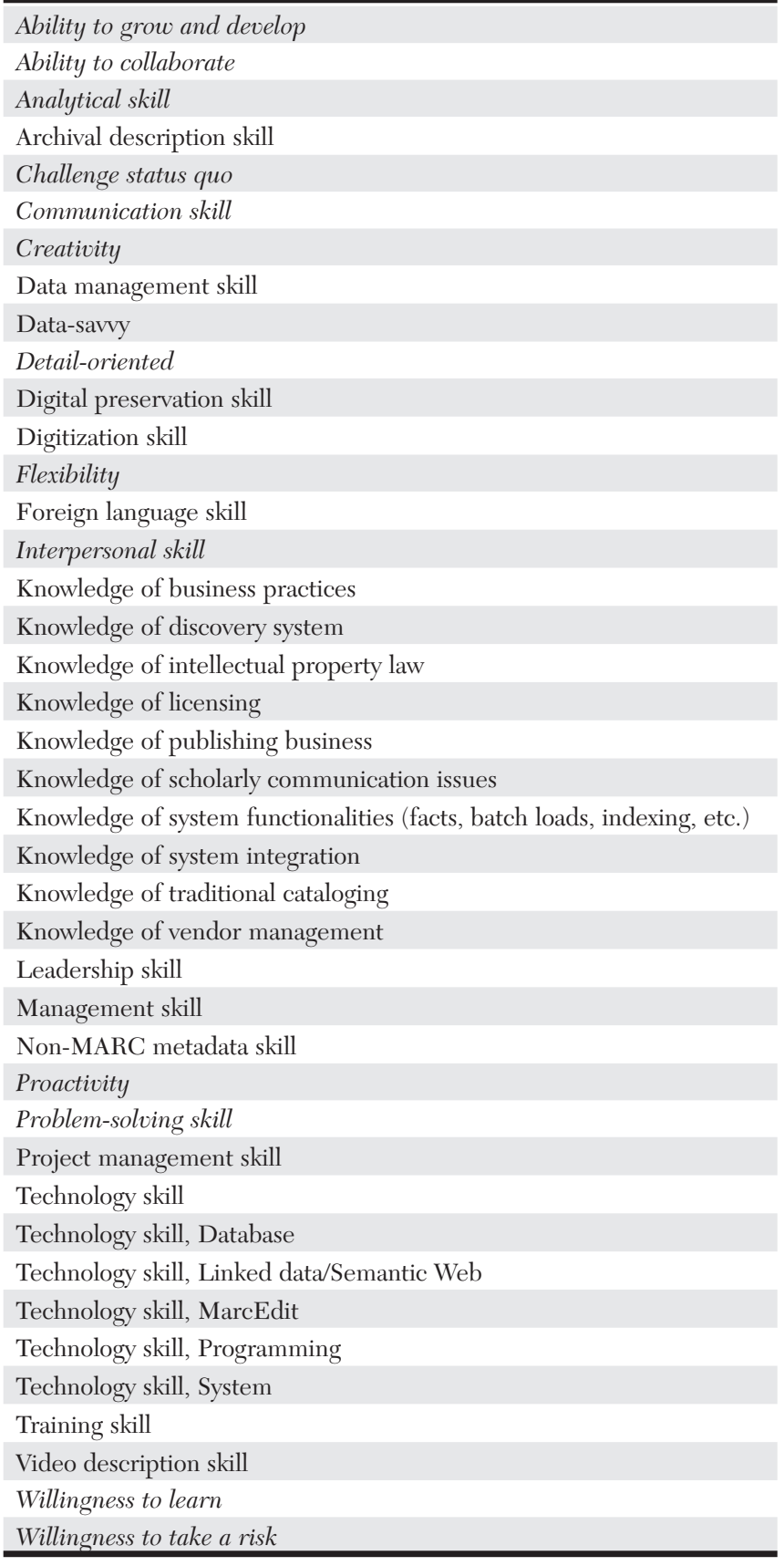

Note: The italicized skills indicate soft skills.

complex in recent years. Dealing with the growing number of digital resources in library collections requires skills such as data management, streaming media, linked data, and data transformation. Managing complex and large-scale projects that require collaboration among library units or with other libraries demands leadership and management skills, particularly in project management. Licensing of e-resources requires knowledge of intellectual property and licensing
Table 4. Change Drivers of Technical Services

\section{By Economy}

Batch purchase in collection development

Change in scholarly communication model

Declining library budget

Increase in Demand-Driven Acquisitions

Increase in outsourcing

Reliance on vendors and publishers for certain library functions (collection development, cataloging, software development, etc.)

\section{By Social Behaviors}

Change in user information seeking behavior Increase in collaborative projects and initiatives Baby boomer retirement

Emphasis on collaboration

Open Access

Copyright issues

Shift from print to digital/electronic resources in library collection

\section{By Technology}

Authority work on the web

Big data management

Change in metadata models

Change in serials life-cycle

Emphasis on access and discovery

Metadata automation

Move toward cloud platform

Reuse of bibliographic data

Shift to BIBFRAME/Linked Data model for library bibliographic data

Technological tools to help increase efficiency (e.g., workflow efficiency tool)

\section{By Academia}

Emphasis on access and discovery of special collections

Metadata consultation

Research data management

Data curation

Evolution of teaching and research

Emphasis on local research collection and repository services

management. It is clear that there is a gap between the skills that are held by current technical services personnel and the skills that are needed for new and emerging technical services functions.

\section{Change Drivers and Challenges}

Many trends and developments in academic libraries were identified during the interviews. These trends and developments are likely the driving factors that are bringing changes to technical services. The author calls these factors "change drivers." Table 4 describes the author's attempt to organize these change drivers based on originating sources-that is, whether they originate in the economy, in technology, in social behaviors, or in academia. It is worth noting that these drivers are not mutually exclusive. For example, "Change in user information seeking behavior" is categorized in By Social Behaviors, but this could easily fit into the By 


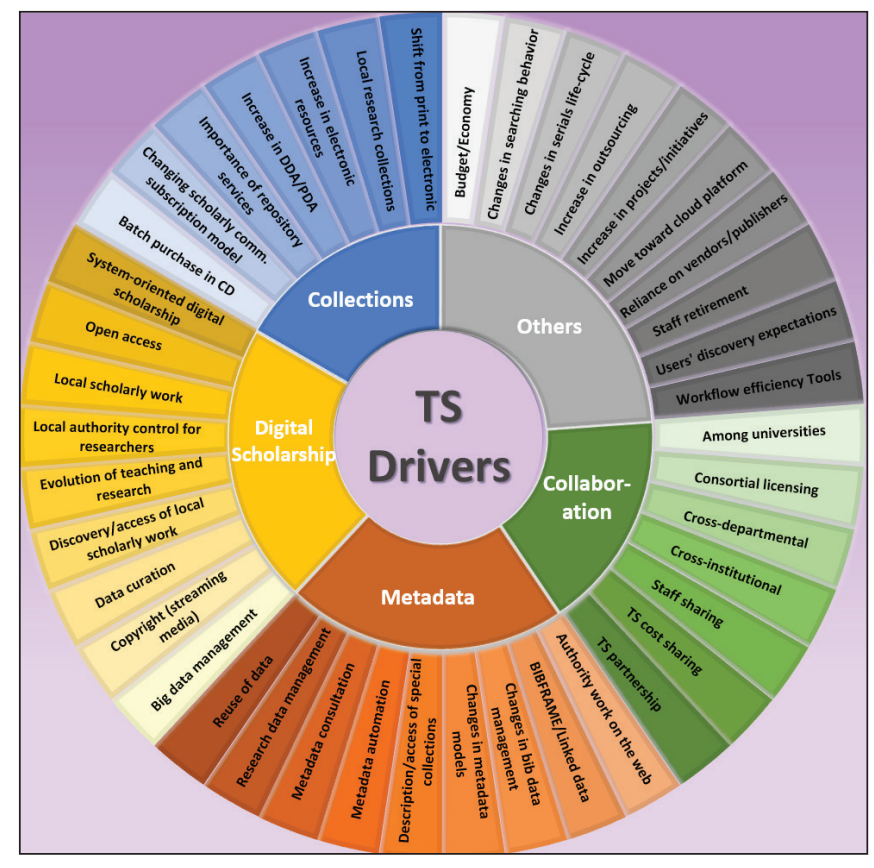

Figure 7. Technical Services Change Drivers by Topical Areas in Academic Libraries

Technology category. Many of these drivers also have causeand-effect relationships. For example, "Declining library budget" can easily be the main cause of all other drivers in the By Economy category plus some change drivers in other categories. Arranging the trends and developments in academic libraries in this way not only provides comprehensive information concerning many external factors that affect technical services, but also reveals the wide range of external factors that have an impact on academic libraries.

When organizing the change drivers based on topics, as shown in figure 7 , the result demonstrates some areas in the libraries that greatly impact technical services. Trends and developments in library collections, digital scholarship, and metadata are likely to be the main change drivers of technical services in academic libraries. One of the participants who identified digital scholarship as a major change driver pointed out, "The way that faculty and other scholars are creating knowledge has changed tremendously, to much more systems oriented, data mining. The way they collaborate with each other has changed. They use different tools. What this means in term of technical services is how do we develop our responsibility to facilitate discovery in ways that promote/support teaching and research in this whole new environment?"

As discussed in the Current Functions section above, collaboration has become a common practice among libraries, and the range of collaboration is quite broad. Some libraries have extensive collaboration among units and departments within the libraries and/or on campus. Others participate in collaborative consortial licensing, collection development, or cataloging. Although the degree of involvement among the libraries in terms of collaboration may vary, it is clear that libraries seek opportunities to collaborate whenever possible.

The change drivers pose both threats and opportunities to technical services. Flat or decreasing library budgets can be a great threat to rigid and inflexible technical services that sustains a status quo. However, these constraints can become the motivation and inspiration for creative and innovative ideas to reconsider and transform antiquated workflows and labor-intensive processes. Lack of technology skills among technical services personnel can be an obstacle for technical services to implement and adapt to new technology, but it can also provide an amazing opportunity to develop a systematic training program for continuing staff development in technical services. The ambivalent nature of these change drivers reflects the current micro-landscape of academic libraries. It is interesting to see how leaders of some academic libraries are seizing these change drivers as opportunities to transform functions and services, including in the area of technical services, in this rapidly changing environment.

\section{Conclusion}

This study found that budget constraints and rapid technological innovations are the major driving forces that have been bringing change to technical services, and these trends are likely to continue into the near future. Efforts to reduce costs result in resolutions to improve existing workflows, which lead to increased efficiency and greater collaboration within the library, on campus, and among universities. Over the last decade, there has been a large shift in expenditures from academic libraries' collection budgets away from print and toward electronic formats. As a result, describing and providing access to e-resources have become one of the major roles of technical services. The rapidly evolving scholarly communication landscape in the digital era and the changing nature of academic libraries' roles also have a significant impact on the functions and organizational structures in technical services. This study revealed that these fiscal and technological challenges can pose threats hindering the progress that we need in technical services, but at the same time they represent tremendous opportunities for us to strengthen technical services' ability to serve our users.

Academic libraries' efforts to transform their technical services functions are evident and libraries are repositioning themselves to support the changing nature of scholarly communication in the midst of fiscal constraints and technological innovation. This study found that a vision 
for strategic directions, and investment in staff resources, including new positions and staff training to bring new skill sets, are key for the successful transformation of technical services. Mandel advised us, "Once your vision is in place, you can start shaping expectations for the staff according to that vision. It is very difficult to do because sometimes you have to resist the temptation of getting the transactions done while you design your new infrastructure. But if you can resist the urge, you will be rewarded with a well-thought-out staffing model and with a strong set of skill sets to support the organization. ${ }^{38}$ Academic libraries need innovative and audacious leadership that encourages library staff to experiment and explore new kinds of library services. They need leadership that inspires innovation and that encourages us to learn from both our successes and mistakes. It is exciting to witness how academic libraries evolve in the midst of this vigorously changing digital age and how leaders at all levels in academic libraries are transforming their libraries to better support research and teaching and to become a crucial strategic partner on campus.

\section{References and Notes}

1. The membership of the Technical Services Directors of Large Research Libraries Interest Group is composed of the twenty-four largest university libraries in Association of Research Libraries (ARL), plus one non-ARL university library, two public libraries, and three national libraries. For the purpose of this study, the author only contacted the twenty five university libraries. They are Columbia University Libraries, Cornell University Library, Duke University Libraries, Harvard Library, Indiana University Libraries, New York University Libraries, Ohio State University Libraries, Penn Libraries, Penn State University Libraries, Princeton University Library, Stanford University Libraries, Texas A\&M University Libraries, University of Alberta Libraries, UC Berkeley Library, UCLA Libraries, University of Chicago Libraries, University of Illinois at Urbana-Champagne Library, University of Michigan Library, University of Minnesota Libraries, University of North Carolina at Chapel Hill Libraries, University of Texas Libraries, University of Toronto Libraries, University of Washington Libraries, University of WisconsinMadison Libraries, and Yale University Library.

2. Maurice F. Tauber and Associates, Technical Services in Libraries: Acquisitions, Cataloging, Classification, Binding, Photographic Reproduction, and Circulation Operations (New York: Columbia University Press, 1954): 11.

3. G. Edward Evans, Sheila S. Intner, and Jean Weihs, Introduction to Technical Services, 7th ed. (Colorado: Libraries Unlimited, 2002): 4.

4. Tauber and Associates, Technical Services in Libraries, 9.

5. Michael Gorman, ed., Technical Services Today and Tomorrow, 2nd ed. (Colorado: Libraries Unlimited, 1998): xv.
6. Ibid., 3

7. Sheila S. Intner with Peggy Johnson, Fundamentals of Technical Services Management (Chicago: American Library Association, 2008): 13.

8. Mary S. Laskowski and Jennifer A. Maddox Abbott, "The Evolution of Technical Services: Learning from the Past and Embracing the Future," Technical Services Quarterly 31, no. 1 (2014): 13-30.

9. Bradford Lee Eden, ed., Innovative Redesign and Reorganization of Library Technical Services: Paths for the Future and Case Studies (Westport, CT: Libraries Unlimited, 2004); Bradford Lee Eden, ed., More Innovative Redesign and Reorganization of Library Technical Services: Paths for the Future and Case Studies (Westport, CT: Libraries Unlimited, 2009).

10. Rosann Bazirjian and Rebecca Mugridge, ed., Teams in Library Technical Services (Lanham, MD: Scarecrow, 2006).

11. Lihong Zhu, "Use of Teams in Technical Services in Academic Libraries," Library Collections, Acquisitions, \& Technical Services 35, no. 2-3 (2011): 81.

12. Carol Joyner Cramer, "All bout Demand-Driven Acquisition," Serials Librarian 65, no. 1 (2013): 88.

13. Zofia E. Brinkman Dzwig, "Innovative Collection Development for E-books at the TU Delft Library," Information Services \& Use 33, no. 1 (2013): 38.

14. Christian Burris, "Demand-Driven Acquisitions: The New Frontier for Technical Services," Technicalities 33, no. 4 (2013): 11-14.

15. William H. Walters, "Patron-Driven Acquisition and the Educational Mission of the Academic Library," Library Resources \& Technical Services 56, no. 3 (2012): 210.

16. International Federation of Library Associations and Institutions, Statement of International Cataloguing Principles (Hague, Netherlands: International Federation of Library Associations and Institutions, 2009): 1, www.ifla.org/files/ assets/cataloguing/icp/icp_2009-en.pdf.

17. Ibid.

18. Ibid.

19. Joint Steering Committee for Development of RDA, "Strategic Plan for RDA, 2005-2009,” accessed February 7, 2015, www.rda-jsc.org/stratplan.html

20. Cathy De Rosa et al., Perceptions of Libraries and Information Resources: A Report to the OCLC Membership (Dublin, OH: OCLC, 2005), www.oclc.org/content/dam/oclc/reports/ pdfs/Percept_all.pdf

21. Roy Tennant, "MARC Must Die," Library Journal 127, no. 17 (2002): 26, http://lj.libraryjournal.com/2002/10/ljarchives/ marc-must-die/.

22. Roy Tennant, "A Bibliographic Infrastructure for the 21st Century," Library Hi Tech 22, no. 2 (2004): 176.

23. Library of Congress, "The Library of Congress Announces Modeling Initiative (May 22, 2012)," accessed February 8, 2015, www.loc.gov/bibframe/news/bibframe-052212.html.

24. Philip Evan Schreur, "The Academy Unbound: Lined Data 
as Revolution," Library Resources \& Technical Services 56, no. 4 (2012): 236.

25. Jake R. Carlson and Jeremy R. Garritano, "E-science, Cyberinfrastructure and the Changing Face of Scholarship: Organizing for New Models of Research Support at the Purdue University Libraries," Research Publications, Paper 137 (Jan. 2010): 8, accessed February 9, 2015, http://docs.lib.purdue .edu/lib_research/137.

26. Ibid, 11 .

27. Carol Tenopir, Ben Birch, and Suzie Allard, "Academic Libraries and Research Data Services: Current Practices and Plans for the Future," white paper, Association of College and Research Libraries, 2012, www.ala.org/acrl/sites/ala.org.acrl/ files/content/publications/whitepapers/Tenopir_Birch_Allard .pdf.

28. Ibid, 19.

29. Ben Hunter, "The Effect of Digital Publishing on Technical Services in University Libraries," Journal of Academic Librarianship 39, no. 1 (2013): 84-93.

30. Carlen Ruschoff, “A New Framework for Technical Services: Interview With New York University's Carol A. Mandel and Martin Kurth," Technicalities 33, no. 5 (2013): 1, 4-7; Carlen Ruschoff, “A New Framework for Technical Services: Part II: Interview With New York University's Carol A. Mandel, Dean and Martin Kurth," Technicalities 33, no. 6 (2013): 1, 3-5.

31. Ibid.

32. The author was a fellow of the 2013-14 ARL Leadership and
Career Develop Program and this research opportunity was provided as part of the program. The preliminary findings of this research were presented at the Technical Services Directors of Large Research Libraries Interest Group during the 2014 ALA Annual Conference, Las Vegas. The author would like to express her gratitude to the ARL Leadership Development Program for this opportunity.

33. A purposive sample is "chosen by the researcher to include representatives from within the population being studied who have a range of characteristics relevant to the research project.” G. E. Gorman and Peter Clayton, Qualitative Research for the Information Professional: A Practical Handbook, 2nd ed. (London: Facet, 2005): 128.

34. Martyn Denscombe, The Good Research Guide: For Smallscale Social Research Projects, 4th ed. (Maidenhead, England: McGraw-Hill/Open University Press, 2010): 175.

35. Elizabeth J. Halcomb and Patricia M. Davidson, "Is Verbatim Transcription of Interview Data Always Necessary?," Applied Nursing Research 19, no. 1 (2006): 38-42.

36. Bradford Lee Eden, "The New User Environment: The End of Technical Servies?," Information Technology \& Libraries 29, no. 2 (2010): 93-100.

37. Sheila S. Intner, “A Technical Services Makeover," Technicalities 27, no. 5 (2007): 1, 14-15.

38. Carlen Ruschoff, "A New Framework for Technical Services, Part II," 5.

\section{Appendix. Interview Questions}

\section{The Name, Technical Services}

1a. Have you thought about changing Technical Services to some other name?

1b. When and why did you rename from Technical Services?

\section{Technical Services Functions}

1. What functions are currently included in the Technical Services area?

2. Which of these functions are new or changed in the last $3-5$ years?

3. Are there functions related to the acquisition, organization, and enabling discovery of content that are actively and routinely occurring elsewhere in the organization?

4. Do you have any functions or areas that you want to change in the future?

\section{Reorganization}

1. When was the last time you restructured the Technical Services area?

2. What was the reason for the last reorganization?

3. What is the rationale behind the current structure of the Technical Services area?

4. Do you plan for restructure in near future (next 3 to 5 years)?

\section{Looking Ahead}

1. What positions have been created in the Technical Services area in the last $3-5$ years?

2. What are some skill sets you are looking for in the Technical Services area?

3. Would you identify some trends and developments that will impact the functions of the Technical Services area?

4. What are things that you want to do or need to do, but can't do; what prevented you from doing it? 